\title{
Modeling for the Spread of Water Pollution under Hydraulic Structure with a Rabbet
}

\author{
A.N. Zinnatullina ${ }^{1}$, M.N. Shamsiev ${ }^{2}$ \\ 1. Kazan State Agricultural University, Kazan, Russia \\ e-mail: zinnatullina-alsu@mail.ru \\ 2. IME - Subdivision of FIC KazanSC of RAS, Kazan, Russia \\ e-mail: MShamsiev@yandex.ru
}

Received: 19 October 2018; Accepted: 9 November 2018; Available online: 15 March 2019

\begin{abstract}
In industry and agriculture, along with the increasing influence of various technogenic factors on the environment, there is an important problem of protecting water resources from pollution and salinization, as well as the problem of protecting natural water bodies from pollutants. The solution of these problems essentially depends on the results of a mathematical study of the mass transfer processes of migrating substances in the filtration of groundwater. In this paper, we simulate the process of spreading water pollution under the hydraulic structure of a complex architecture. The unsteady equation of the process of mass transfer of pollutants during the filtration of groundwater was approximated by the finite difference method, while the procedure "weighting upstream" was used to approximate the convective terms. The results of calculations showed that the pollution of the downstream of a hydraulic structure depends on the number of rabbets and their location along the underground circuit. The obtained results can be used in monitoring and building predictive estimates of the migration regime of pollution under a hydraulic structure in real time.
\end{abstract}

Keywords: Hydraulic structure; Rabbet; Filtration; Pollution.

\section{Introduction}

Methods of studying environmental safety problems are currently developing rapidly. The basis for identifying the environmental situation and developing measures for the prevention and elimination of pollution is: conducting comprehensive monitoring and detailed examination of polluted land and groundwater, unifying a number of parameters and methods to clean the soil from pollution, including building computer mathematical models to determine the degree pollution.

In this regard, the study of filtration processes in aquifers of untreated sewage, liquid waste from petroleum, chemical and other industries, agriculture is an important area. The construction of computer mathematical models makes it possible to predict the formation of a pollution front and to estimate the size of a polluted area. Mathematical modeling immeasurably expands the possibilities of the latter both in its basic research and in the field of its practical applications. Mathematical models of the process of mass transfer of migrating substances were developed in [1-4].

A common feature of all these processes is the mechanism of substance transfer in a porous medium by a filtration flow associated with convective diffusion. The propagation processes of migrating substances under a hydraulic structure have been considered in [5-7].

This paper considers a mathematical model of the process of groundwater pollution under a dam with a tongue, the underground contour of which is given in the form of a polygon. The regional task in this case is characterized by the complex geometry of the underground contour of the hydraulic structure and the appearance of additional conditions within the computational domain.

\section{Formulation of the problem}

The process of mass transfer in the filtration of groundwater under a hydraulic structure with a complex underground circuit (Fig. 1) is described by a differential equation [3,7]:

$$
D_{x} \frac{\partial^{2} c}{\partial x^{2}}+D_{y} \frac{\partial^{2} c}{\partial y^{2}}-V_{x} \frac{\partial c}{\partial x}-V_{y} \frac{\partial c}{\partial y}=\sigma \frac{\partial c}{\partial t},(x, y) \in Z, t \in(0, T],
$$


with initial

$$
c(x, y, 0)=c(x, y)
$$

and boundary conditions

$$
\begin{aligned}
& \left.c(x, y, t)\right|_{A B}=\lambda(x, t), \\
& \left.\frac{\partial c}{\partial y}\right|_{C D}=0\left(\left.\operatorname{or} c(x, y, t)\right|_{C D}=v(x, t)\right), \\
& \left.\frac{\partial c}{\partial n}\right|_{L_{1}}=\left.\frac{\partial c}{\partial n}\right|_{L_{2}}=0
\end{aligned}
$$

where, $D_{x}$ and $D_{y}$ are the convective diffusion coefficients, $\sigma$ is the active porosity, $Z$ is the filtration area, $A B$ and $C D$ are the upper and lower bounds respectively, $l_{x}$ and $l_{y}$ are the length and depth of the dam's underground contour, and the length and depth of the filtration area (the depth of the filtration area is chosen so that did not introduce an error in the solution of the problem), $l_{1}$ and $l_{2}$ are the depth and width of the tongue, $\lambda(x, t)$ and $v(x, t)$ are the concentration of soluble substances in the pollution source and in the wastewater basin respectively, which, in the general case, are piecewise continuous functions, $h$ is pressure acting filtering coefficients, $k_{x}, k_{y}$ are filtration coefficients, $V_{x}, V_{y}$ are filtration flow velocity components under hydraulic structure, $L_{1}=A E \cup$ $E F \cup D F$ is the boundary of filtration, $L_{2}=B B_{1} \cup B_{1} B_{2} \cup B_{2} B_{3} \cup B_{3} C_{3} \cup C_{2} C_{3} \cup C_{1} C_{2} \cup C C_{1}$ is the boundary contour of underground dam with the tongue.

To calculate the components of the rate of filtration flows under the hydraulic structure

$$
V_{x}=-k_{x} \frac{\partial h}{\partial x}, V_{y}=-k_{y} \frac{\partial h}{\partial y}
$$

The stationary problem in the region is solved (Fig. 1)

$$
k_{x} \frac{\partial^{2} h}{\partial x^{2}}+k_{y} \frac{\partial^{2} h}{\partial y^{2}}=0,(x, y) \in Z
$$

with boundary conditions:

$$
\left.h(x, y)\right|_{A B}=H_{1},\left.h(x, y)\right|_{C D}=H_{2},\left.\frac{\partial h}{\partial n}\right|_{L_{1}}=\left.\frac{\partial h}{\partial n}\right|_{L_{2}}=0
$$

where $H_{1}, H_{2}$ are the values of the pressures on the upper and lower pools.

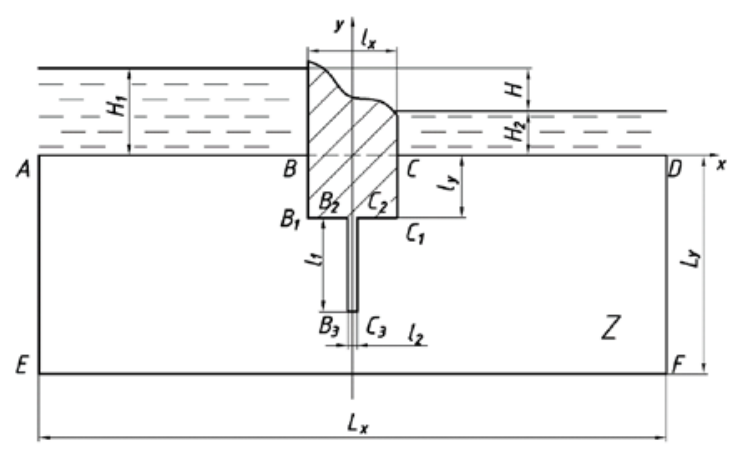

Fig. 1. Scheme of hydraulic structures with rabbet

\section{Calculation results}

A model example is considered with the following physical and geometrical parameters: $H_{1}=10 \mathrm{~m}, H_{2}=5 \mathrm{~m}$, $\sigma=0,4, L_{x}=40 \mathrm{~m}, L_{y}=20 \mathrm{~m}, l_{x}=3 \mathrm{~m}, l_{y}=2 \mathrm{~m}, D_{x}=0,1 \mathrm{~m}^{2} /$ day, $D_{y}=0,1 \mathrm{~m}^{2} /$ day, $k_{x}=1,0 \mathrm{~m} /$ day, $k_{y}=$ $1,0 \mathrm{~m} /$ day, $c(x, y, 0)=0, \lambda(x, t)=1$. The influence of the number of grooves located under the hydraulic structure and their location with respect to the underground circuit on the filtration processes and the spread of pollution is investigated. 
The calculations were carried out at different positions of the rabbet under the underground contour of the dam (left, right and in the middle). In fig. 2 shows the pressure field and the concentration field for the left dowel depth $2 \mathrm{~m}$ at the time $T=30$ days. From the obtained results, it follows that the optimal position is the position of the rabbet on the left (Fig. 2), since in this case the pollution reaches the lower pool boundary more slowly than in other cases. This fact is confirmed by the dependence of the mass flow rate of pollution passing through the downstream boundary. In fig. 3 shows the curves of mass flow rate of pollution for different positions of the rabbet. In the presence of the left rabbet, the flow of the migrating substance into the lower pool is less than in other cases. The mass flow rate of the pollutant through the platform of unit downstream width is calculated by the formula:

$$
\Delta Q=c \cdot(\rho \vec{V} \cdot \vec{n}) \cdot \Delta S
$$

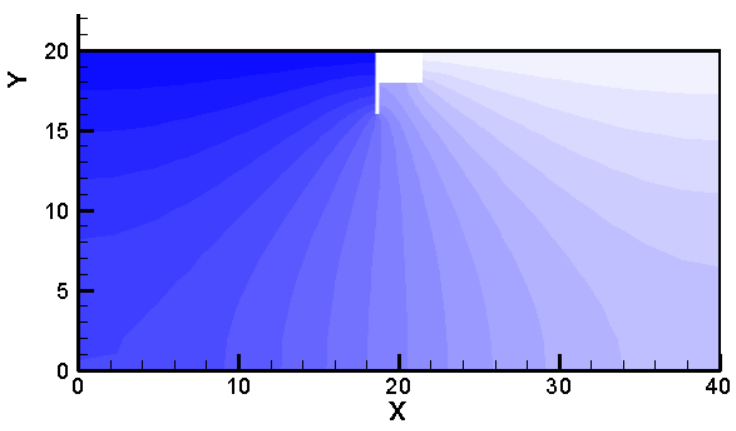

a)

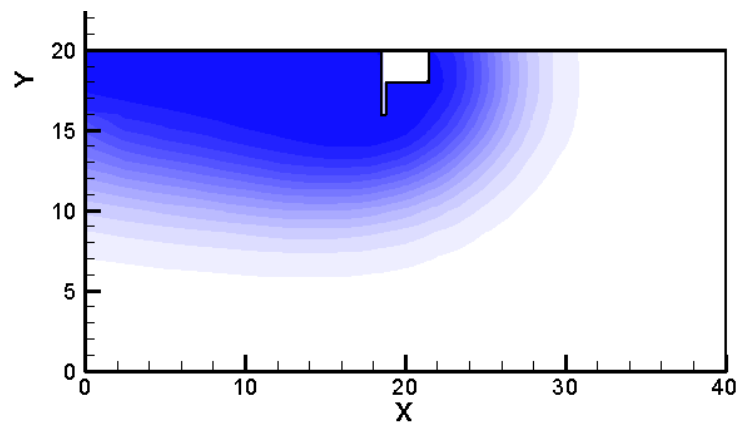

b)

Fig. 2. a) Pressure field and $b$ ) concentration field at $T=30$ days

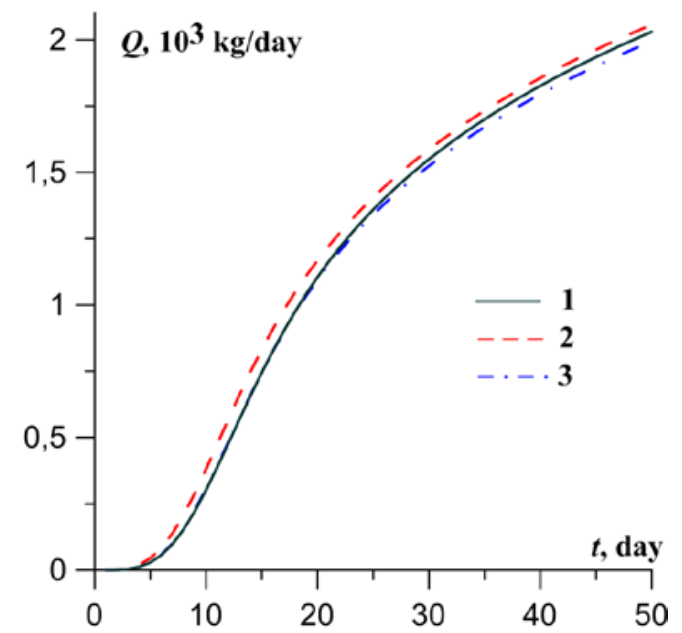

Fig. 3. Changing the flow rate of pollution in the downstream. 1 - the location of the rabbet on the right; 2 - the location of the rabbet in the middle; 3 - the location of the rabbet on the left

The proposed model also allows to obtain the result in the case of a finite number of dowels of different depths, and the calculated models of hydraulic structures with two rabbets of the same depth were considered. In fig. 4 shows the pressure field and the concentration field in the case of two rabbets of the same depth (2 m) at the time $T=30$ days. The results of calculations show that the process of spreading pollution depends on the position and length of the rabbets. For comparison, the case of a dam without a rabbet with parameters $l_{x}=3 \mathrm{~m}$ and $l_{y}=4 \mathrm{~m}$ is calculated. In Fig. 5 shows the pressure field and the concentration field at the time $T=30$ days for this dam. In fig. 6 shows the curves of the flow rate of pollution passing through the downstream boundary in the case of a hydraulic structure with two rabbets, without rabbets and with one rabbet located to the left. From the obtained results it follows that the presence of two rabbets slows down the process of spreading pollution better than in the other two cases.

\section{Conclusions}

Using model examples, the process of pollution spreading under a hydraulic structure with a complex underground circuit has been investigated. The results of calculations show that pollution of the downstream of a 
hydraulic structure depends on the number of rabbets and their location along the underground circuit. The obtained results can be used in monitoring and building predictive estimates of the migration regime of pollution under a hydraulic structure in real time.

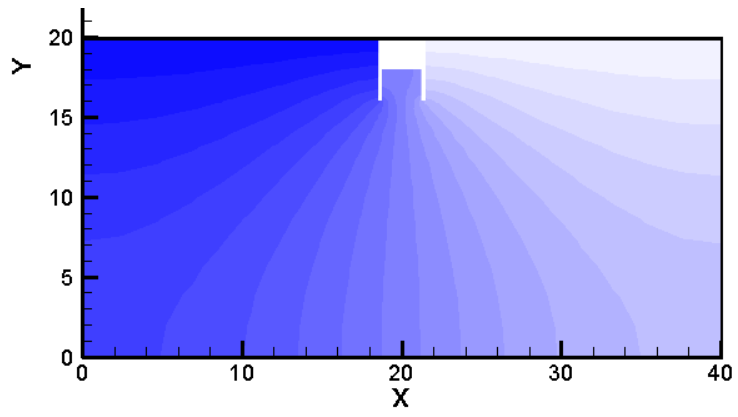

a)

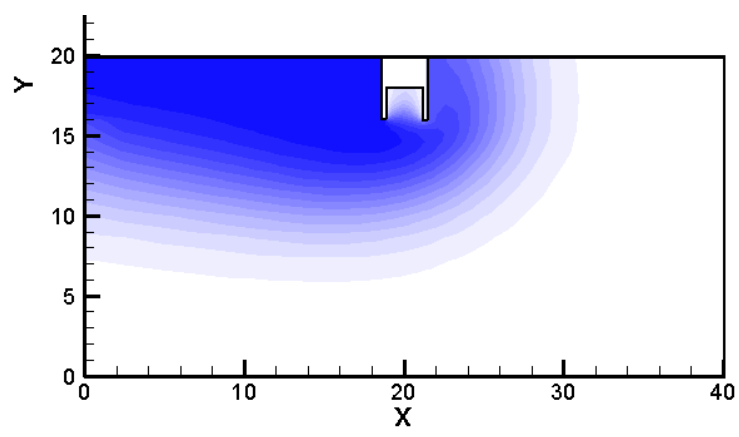

b)

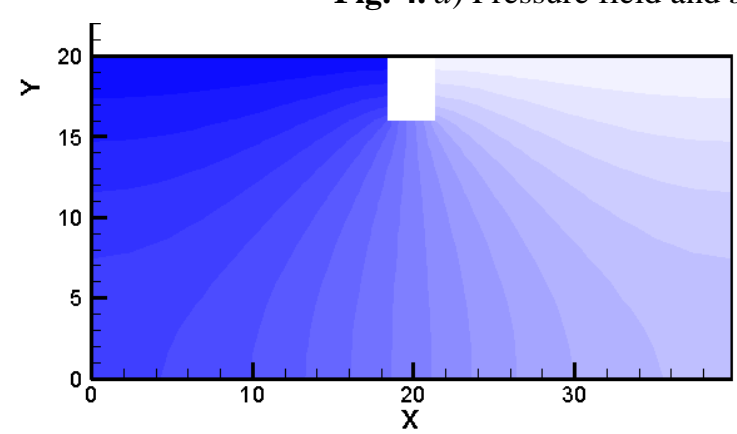

a)

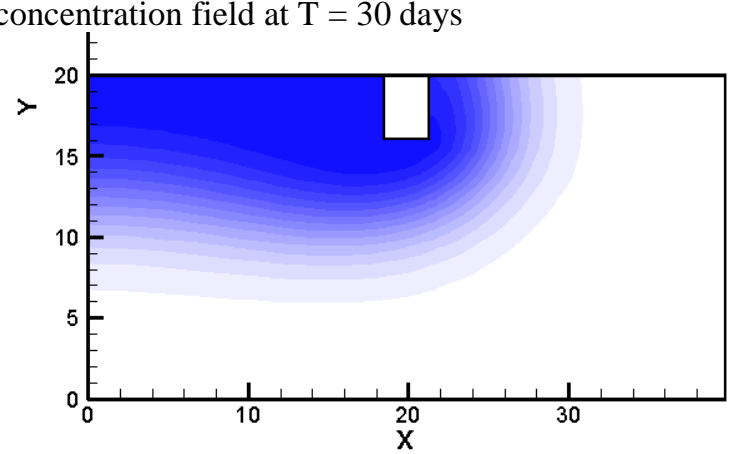

b)

Fig. 5. a) Pressure field and $b$ ) concentration field at $\mathrm{T}=30$ days

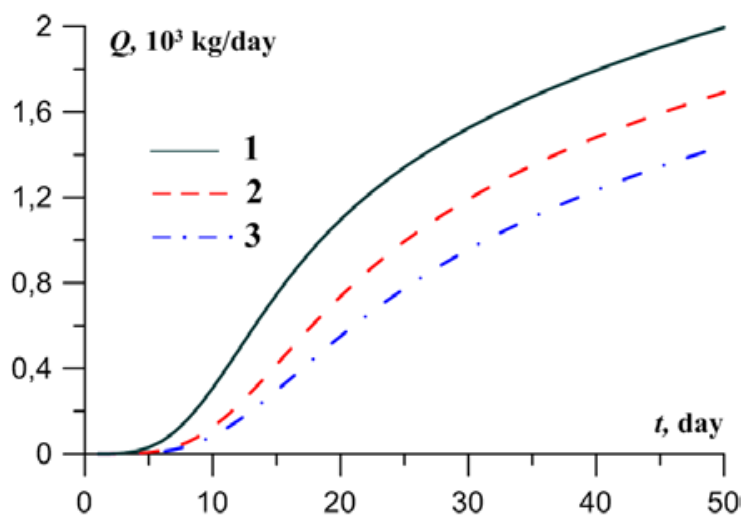

Fig. 6. Changing the flow rate of pollution in the downstream. 1 - hydraulic construction with a rabbet of $2 \mathrm{~m}$ with a left-side rabbet $2 \mathrm{~m}$ long; 2 - hydraulic structure with a depth of $4 \mathrm{~m}$; 3 - hydraulic construction with a depth of $2 \mathrm{~m}$ with left and right rabbets $2 \mathrm{~m}$ long

\section{References}

[1] Bochever FM, Lapshin NN, Oradkovskaya AE. Groundwater protection from pollution. Nedra;1979. p. 254.

[2] Baer J, Zaslavsky D, Irmey S. Physical and mathematical foundations of water filtration. Mir; 1971 . p.451.

[3] Mironenko VA. Groundwater dynamics: a textbook. 3rd ed. Publishing House of the Moscow State Mining University; 2001. p.519.

[4] Fried J. Pollution of groundwater. Nedra; 1981. p. 304.

[5] Zinnatullina AN, Shamsiev MN, Sheshukov EG. Numerical modeling of the process of pollution spreading under hydraulic construction. Bulletin of Kazan Technological University. 2013;16 (1):257-258.

[6] Zinnatullina AN, Ibjatov RI, Shamsiev MN. Mathematical modeling of the spread of pollution under a hydraulic structure with a tongue.In: Proceedings of the XXVII International Scientific Conference 
"Mathematical Methods in Engineering and Technologies",MMTT-27,T.7. Tambov: Tambovsk State Technical University; 2014. P.43-47.

[7] Zinnatullina AN, Shamsiev MN, Ibyatov RI. Simulating a pollution process in water filtration under a hydraulic structure. Mathematical Models and Computer Simulations. 2015;7 (3): 254-258.

(C) 2019 by the author(s). This work is licensed under a Creative Commons Attribution 4.0 International License (http://creativecommons.org/licenses/by/4.0/). Authors retain copyright of their work, with first publication rights granted to Tech Reviews Ltd. 